\title{
Effects of Par-Frying and Calcium Propionate on the Quality of Frozen Curry Puff
}

\author{
Norhayati Hussain $^{1,2 *}$, Izzreen Ishak ${ }^{2,3}$, Nurul Syafizan Rosle ${ }^{1}$, Nurul Husna Mohamed ${ }^{1}$, Maaruf Abd Ghani ${ }^{3}$ \\ ${ }^{I}$ Department of Food Technology, Faculty of Food Science and Technology, Universiti Putra Malaysia, 43400 Serdang, Selangor, \\ Malaysia \\ ${ }^{2}$ Halal Products Research Institute, Putra Infoport, 43400 UPM Serdang, Selangor, Malaysia \\ ${ }^{3}$ Innovation Centre for Confectionery Technology (MANIS), Faculty of Science and Technology, Universiti Kebangsaan Malaysia, 43600 \\ Bangi, Selangor, Malaysia \\ *Corresponding author E-mail: aryatihussain@upm.edu.my.
}

\begin{abstract}
This study proves that the application of par-frying method and addition of calcium propionate able to prolong the shelf life and preserve the quality of frozen pastry curry puff during distribution and storage after exposure to fluctuating temperature. Par-fried curry puff added with $0.1 \%$ calcium propionate produce lower moisture content, oil uptake and weight loss than non-par fried puff. In addition, par fried curry puff was capable of preventing any visible black spots (after 4 weeks storage) which are related to the quality defect. No sensorial changes detected during sensory evaluation in terms of texture, appearance, taste and overall acceptability after addition of calcium propionate. There is a high possibility of frozen curry puff to be commercialized internationally without any deterioration.
\end{abstract}

Keywords: Par-frying, Calcium Propionate, Frozen Pastry, Sensory, Curry Puff

\section{Introduction}

The global demand and consumption of frozen food market are predicted to increase at a compound annual growth rate (CAGR) of $4 \%$ by 2019 [1]. Due to the change in lifestyle, consumers prefer more convenience foods for on-the-go consumption rather than preparing everything from the scratch. Preferences for pastries consumptions are also increasing in the current lifestyle, thus creating the interest for the food manufacturers to manufacture more ready-to-bake frozen pastries to supply in the food service industry and to be sold in the market [2].

Curry puff is a traditional Malaysian pastry and is consumed after deep-frying. It is widely sold in supermarkets and the food service industry. However, it is easily spoiled due to its soft texture during thawing. Kasetsart [3] stated that fluctuations of temperature ($18^{\circ} \mathrm{C},-13^{\circ} \mathrm{C}$, and $-8^{\circ} \mathrm{C}$ ) may reduce its shelf life, thus affecting its end product quality. Black spots may be detected on the curry puff surface, further reducing the product quality. Bakery products are prone to spoilage which includes physical, chemical, and microbial spoilage [4]. Temperature fluctuation in bakery products due to poor handling during storage may lead to loss of dough strength, thus reducing the quality in the final product [3]. Guynot et al. [5] stated that $1 \%$ to $5 \%$ of bakery products are spoiled, depending on the product type and its processing method.

According to the European Food Safety Authority (EFSA) [6], calcium propionate $(\mathrm{CP})$ is defined as organic salt with molecular formula $\mathrm{C}_{6} \mathrm{H}_{10} \mathrm{O}_{4} \mathrm{Ca}$. Belz et al. [7] and Khaldun et al. [8] stated that $\mathrm{CP}$, propionic acid, and propionates are usually used in bakery products due to their antimicrobial effects. Kirbaslar et al. [9] reported that propionic salts are listed as "generally recognized as safe (GRAS)" food additives. Apart from adding preservatives, pre-drying and par-frying the food is one of the methods to reduce the moisture content to prolong the shelf life of the food. According to Lonn et al. [10], pre-drying, which includes a par-frying step, improves texture and reduces oil uptake. Raj et al. [11] define par-frying as a process where the product is partially fried, followed by storage in a freezer until it reaches the end consumers or restaurants. Many street food vendors in Malaysia use frying process for cooking which includes the frying of curry puffs. Hence, the addition of preservatives and par-frying process are believed to reduce the presence of black spots on curry puff skin after frozen storage at $-18^{\circ} \mathrm{C}$. Thus, the objective of this study to focus on the effect of par-frying and permitted preservative towards the physicochemical properties and sensory attributes of the frozen curry puff.

\section{Materials and methods}

\subsection{Materials}

Bleached wheat flour, margarine, fat, cooking oil, and curry puff filling were supplied by Doana Frozen Food from Kota Tinggi, Johor, Malaysia. Salt and monosodium glutamate were purchased from Tesco, IOI City Mall Putrajaya, Malaysia.

\subsection{Preparation of curry puff}

The curry puff skin was prepared according to the recipe provided by Doana Frozen Food. Two types of dough were formulated: the addition of $0.1 \% \mathrm{CP}$ and without the addition of $\mathrm{CP}$ (control). The ingredients were mixed using a mixer (Aikosha, China) and kept at room temperature $\left(25^{\circ} \mathrm{C}\right)$ before resting for $15 \mathrm{~min}$. Next, the dough was rolled using a sheeter (Ampia Brevettata, Italy) and cut into square pieces using a knife followed by moulding using curry 
puff moulder and later, filled with potato curry filling (provided by Doana Frozen Food, Johor, Malaysia). The two formulated dough for the curry puff skin was further analyzed as par-fried (PF) and non-par-fried (NPF). The samples were par-fried in the deep fryer (Philux, China) using palm cooking oil (Tiara, Felda Global Venture, Malaysia). The different par-frying duration (1 min, 2 min and $3 \mathrm{~min}$ ) for $\mathrm{PF}_{1}$ (par-fried curry puff without the incorporation of $\mathrm{CP}$ ) and $\mathrm{PF}_{2}$ (par-fried curry puff with the addition of $0.1 \%$ $\mathrm{CP}$ ) were carried out to determine the optimal frying time. Melito and Farkas (2013) used a total of $64 \mathrm{~s}$ duration time to par-fry four doughnuts. A slight modification was done by frying the PF curry puffs in hot oil at $180^{\circ} \mathrm{C}$ for $2 \mathrm{~min}$. All formulations were labelled accordingly as $\mathrm{NPF}_{1}$ : non-par-fried/control, $\mathrm{NPF}_{2}$ : non-par-fried with $0.1 \% \mathrm{CP}, \mathrm{PF}_{1}$ : par-fried/control, and $\mathrm{PF}_{2}$ : par-fried with $0.1 \%$ $\mathrm{CP}$. The curry puff samples were stored in a freezer at $-18^{\circ} \mathrm{C}$ for further analysis.

\subsection{Frying the curry puffs}

The NPF and PF curry puffs were thawed before frying. Both PF and NPF curry puffs were fried at $180^{\circ} \mathrm{C}$ using a deep fryer (Philux, China). Preliminary studies were also conducted at this stage to determine the optimal frying time (after frozen) for both PF (2.0 min, $2.5 \mathrm{~min}, 3.0 \mathrm{~min}$ ) and NPF (4 min, $5 \mathrm{~min}, 6 \mathrm{~min}$ ) curry puffs. Based on the preliminary studies, NPF curry puff was fried for 5 min._and PF curry puff was fried for 2 min

\subsection{Moisture}

Moisture of both PF and NPF curry puffs were determined by referring to AOAC [13] (Method 925.40) via oven drying (Binder, Germany).

\subsection{Crude fat and oil uptake}

Crude fat content and oil uptake were determined according to AOAC [13] (Method 920.39) by Soxhlet method to compare between the NPF and PF curry puffs.

\subsection{Total polar compound (TPC)}

Total polar compounds in oil used for par-frying the curry puff (PF1) was measured with Testo 265 (Testo Inc., Germany) according to Lemos et al. [14] to determine the limits. TPC was analyzed during the fifteenth time of par-frying.

\subsection{Colour}

Colour parameters (L, a, b) were measured with a colourimeter (Konica Minolta, Japan) according to Ferreira et al. [15].

\subsection{Weight loss and image analysis}

Weight loss analysis was performed to observe the weight changes during frozen storage. Both PF and NPF curry puffs were subjected to temperature fluctuation based on Ding et al. [16] method with some modifications $\left(25 \pm 2^{\circ} \mathrm{C}, 25 \pm 4^{\circ} \mathrm{C}, 25 \pm 6^{\circ} \mathrm{C}, 25 \pm 8^{\circ} \mathrm{C}\right.$, and $25 \pm 10^{\circ} \mathrm{C}$ ). Image analysis was done using a microscope with 40× magnification (Meiji, Japan) concurrently with the weight loss analysis. The images of thawed curry puffs were observed weekly for 4 cycles to detect the presence of black spot on the surface of both NPF and PF curry puffs.

\subsection{Sensory evaluation}

The sensory analysis was conducted using 50 untrained panellists which consisted of university students and staffs from Universiti Putra Malaysia. The curry puffs were produced 2 days earlier and kept at $-18^{\circ} \mathrm{C}$. Panellists were asked to evaluate a 9-point hedonic scale ( $1=$ extremely dislike; $9=$ extremely like) as described by Melito \& Farkas [12]. The panellists had to score the curry puffs in terms of appearance, texture, taste, and overall acceptability.

\subsection{Statistical analysis}

Each type of analysis was performed in triplicates. Statistical analysis and comparison of means were carried out using the Minitab 16.0 (2014) (Minitab Inc., USA). The data collected were examined by one-way ANOVA. The Tukey's test was used to compare the means and the differences were considered significant at the level of $\mathrm{p}<0.05$.

\section{Results and discussion}

\subsection{Moisture, crude fat and oil uptake}

Table 1 shows that the $\mathrm{NPF}_{1}$ curry puff had significantly the highest percentage of moisture $(\mathrm{p}<0.05)$ compared to $\mathrm{PF}_{1}$ curry puff after frying. Moisture contents in $\mathrm{NPF}_{1}$ and $\mathrm{NPF}_{2}$ curry puffs before frying were significantly high $(\mathrm{p}<0.05)$ compared to $\mathrm{NPF}_{1}$ and $\mathrm{NPF}_{2}$ curry puffs after frying. During par-frying, most of the moisture in curry puffs evaporated into the oil and were further removed during frozen storage [11]. According to Mohamed et al. [17], moisture content shows a significant effect on the product crispiness. Sanz et al. [18] stated that par-frying causes the moisture to be reduced inside French fries, hence making the product crispier than the non-par-fried products. They also stated that the NPF French fries needed longer frying time in order to remove moisture from the dough to become crispy. Therefore, lower moisture content in the curry puff after frying is more desirable as it produced crispier texture for PF curry puff compared to the NPF curry puff.

Table 1: Comparison of the moisture content of NPF and PF curry puffs Type of $\quad$ Moisture (\%) $\quad$ Moisture (\%) $\quad$ Moisture loss sample (before frying) (after frying) (\%) (before

\begin{tabular}{cccc} 
& & & $\begin{array}{c}\text { frying - after } \\
\text { frying) }\end{array}$ \\
\hline $\mathrm{NPF}_{1}$ & $19.32 \pm 0.21^{\mathrm{a}}$ & $13.49 \pm 0.067^{\mathrm{a}}$ & 5.83 \\
$\mathrm{NPF}_{2}$ & $17.92 \pm 1.01^{\mathrm{c}}$ & $11.66 \pm 0.36^{\mathrm{c}}$ & 6.26 \\
$\mathrm{PF}_{1}$ & $11.67 \pm 0.08^{\mathrm{b}}$ & $7.61 \pm 0.065^{\mathrm{b}}$ & 4.06 \\
$\mathrm{PF}_{2}$ & $10.57 \pm 0.16^{\mathrm{b}}$ & $7.64 \pm 0.25^{\mathrm{b}}$ & 2.93 \\
\hline
\end{tabular}

$\mathrm{NPF}_{1}$ : non par-fried (control), $\mathrm{NPF}_{2}$ : non par-fried with $0.1 \% \mathrm{CP}$,

$\mathrm{PF}_{1}$ : par-fried (control), $\mathrm{PF}_{2}$ : par-fried with $0.1 \% \mathrm{CP}$

${ }^{\mathrm{a}-\mathrm{c}}$ Different alphabets within the same column are significantly different by Tukey's test $(\mathrm{p}<0.05)$.

Values are mean \pm SD of triplicates.

Table 2 shows that the crude fat content was significantly the lowest $(\mathrm{p}<0.05)$ in fried $\mathrm{NPF}_{1}$ curry puff compared to $\mathrm{PF}_{2}$ curry puff. In addition, $\mathrm{NPF}_{1}$ curry puff had significantly the lowest crude fat content in un-fried curry puff (before frying) compared to $\mathrm{PF}_{2}$ curry puff. Table 2 also shows a significant difference $(p<0.05)$ of oil uptake between NPF and PF curry puffs after frying. The $\mathrm{NPF}_{1}$ and $\mathrm{NPF}_{2}$ curry puffs showed higher oil uptake than $\mathrm{PF}_{1}$ and $\mathrm{PF}_{2}$ curry puffs. Melito and Farkas [12] stated that deep frying took a shorter time $(32 \mathrm{~s})$ at $182^{\circ} \mathrm{C}$, leading to lesser oil uptake in French fries. From this study, longer time $(5 \mathrm{~min})$ was required to fry NPF curry puffs until fully cooked compared to the PF curry puffs that required only $2 \mathrm{~min}$ to be completely cooked before serving.

Moisture content plays a major role in how much oil in the food product is absorbed during the frying process. The moisture needs to be sufficient for the vapour to be carried out to the crust continuously, thus leaving the exposed area void for the fat to enter when frying. This might be related to moisture content and oil uptake of the $\mathrm{NPF}_{1}$ curry puff which was the highest compared to other types of the sample during frying. In addition, an increase in moisture loss contributes to the high-fat uptake of the product [19]. In this study, high moisture content in $\mathrm{NPF}_{1}$ and $\mathrm{NPF}_{2}$ curry 
puffs led to a higher percentage of moisture loss in non-par-fried than par-fried samples. Therefore, the high moisture content resulted in higher oil uptake during frying in NPF curry puffs compared to the PF curry puffs.

Table 2: Crude fat and oil uptake analysis of NPF and PF curry puffs during and after frying

\begin{tabular}{cccc}
\hline Type of sample & $\begin{array}{c}\text { Crude Fat (be- } \\
\text { fore frying) }\end{array}$ & $\begin{array}{c}\text { Crude Fat } \\
\text { (after frying) }\end{array}$ & $\begin{array}{c}\text { Oil Uptake (dur- } \\
\text { ing frying) }\end{array}$ \\
\hline $\mathrm{NPF}_{1}$ & $6.44 \pm 0.04^{\mathrm{d}}$ & $14.03 \pm 0.02^{\mathrm{d}}$ & $39.24 \pm 0.15^{\mathrm{b}}$ \\
$\mathrm{NPF}_{2}$ & $10.59 \pm 0.29^{\mathrm{c}}$ & $15.28 \pm 0.02^{\mathrm{c}}$ & $37.41 \pm 0.39^{\mathrm{b}}$ \\
$\mathrm{PF}_{1}$ & $13.65 \pm 1.09^{\mathrm{a}}$ & $16.13 \pm 0.01^{\mathrm{b}}$ & $26.29 \pm 0.49^{\mathrm{a}}$ \\
$\mathrm{PF}_{2}$ & $14.41 \pm 0.29^{\mathrm{b}}$ & $18.80 \pm 0.07^{\mathrm{a}}$ & $28.91 \pm 6.76^{\mathrm{a}}$ \\
\hline
\end{tabular}

$\mathrm{NPF}_{1}$ : non par-fried (control), $\mathrm{NPF}_{2}$ : non par-fried with $0.1 \% \mathrm{CP}$,

$\mathrm{PF}_{1}$ : par-fried (control), $\mathrm{PF}_{2}$ : par-fried with $0.1 \% \mathrm{CP}$

${ }^{\mathrm{a}-\mathrm{d}}$ Different alphabets within the same column are significantly different by Tukey's test $(\mathrm{p}<0.05)$.

Values are mean \pm SD of triplicates.

\subsection{Total polar compounds (TPC)}

Table 3 shows a significant difference $(\mathrm{p}<0.05)$ in TPC between the fresh oil and the oil at the tenth and fifteenth frying of the parfried curry puff $\left(\mathrm{PF}_{1}\right)$. The percentage of TPC in the fresh oil increased until the fifteenth time of par-frying. TPC was found to increase with the repeated frying using the same oil [20].

Table 3: Total polar content (TPC) during frying of $\mathrm{PF}_{1}$ curry puff (fresh oil until 15 th time)

\begin{tabular}{cc}
\hline Frying & TPC $(\%)$ \\
\hline Fresh oil & $12.43 \pm 0.90^{\mathrm{a}}$ \\
$5^{\text {th }}$ time & $13.63 \pm 0.51^{\mathrm{a}}$ \\
$10^{\text {th }}$ time & $18.00 \pm 0.50^{\mathrm{b}}$ \\
$15^{\text {th }}$ time & $21.00 \pm 0.50^{\mathrm{c}}$ \\
\hline
\end{tabular}

${ }^{\mathrm{a}-\mathrm{c}}$ Different alphabets within the same column are significantly different by Tukey's test $(\mathrm{p}<0.05)$.

Values are mean \pm SD of triplicates.

According to Chatzilazarao et al. [21], a total polar compound in oil has a linear relationship with the repeated usage of frying oil. They also stated that there was a high amount of polar compound present in the hot oil when frying the French fries. Chen et al. [22] stated that during frying of pork chop, French fries, and chicken leg fillet, thermal reaction and oxidation of oil occur and produce polar compounds. Oil is degraded due to the release of water and fat into the frying oil during the frying process [23]. Therefore, the frying condition should be controlled since the frying oil is easily degraded by the presence of food in the frying oil [22]. Deora et al. [20] stated that polar compound determination in used oils is a well-accepted method due to its accuracy and reproducibility. TPC measures the extent of deterioration in frying oil in most situations [24]. Aladedunye and Przybylski [25] stated that TPC is more polar than triacylglycerol and considered as the non-volatile compound that resulted from thermal, hydrolytic, and oxidative alteration. According to Weisshaar [26], the TPC value should be less than $25 \%$ for the assessment of used frying oils. However, in this study, the oil used to par-fry the curry puff $\left(\mathrm{PF}_{1}\right)$ was still at an acceptable level (less than 25\%) even after the 15th time of parfrying. Chen et al. [22] reported that after $48 \mathrm{~h}$ of frying pork chop, chicken fillet, and French fries using palm oil, the TPC value increased from $11.3 \%$ to almost $30 \%$ which was found to exceed the maximum TPC limit (exceeding $25 \%$ ) set by the Taiwan regulation. Melck et al. [27] also reported that the TPC value was $31.8 \%$ from the palm oil which was collected from restaurants after six days of frying. The TPC value exceeded the $24 \%$ limit based on the German regulations.

\subsection{Colour}

Effect of frying the NPF and PF curry puffs were analyzed using the colour analyzer. Table 4 shows $b^{*}$ (yellow to blue) values with no significant difference $(\mathrm{p}>0.05)$ between the NPF and PF sam- ples. However, for $\mathrm{a}^{*}$ (red to green) and $\mathrm{L}^{*}$ (lightness) value, the only $\mathrm{PF}_{2}$ sample showed a significant difference $(\mathrm{p}<0.05)$ compared to other samples.

Table 4: Comparison of the colour of PF and NPF curry puff skin

\begin{tabular}{ccccc} 
Types of & \multicolumn{4}{c}{ Color index } \\
\cline { 2 - 5 } Sample & $\mathrm{L}^{*}$ & $\mathrm{a}^{*}$ & $\mathrm{~b}^{*}$ & $\Delta \mathrm{E}$ \\
\cline { 2 - 5 } & $60.2 \pm 0.6^{\mathrm{b}}$ & $11.9 \pm 0.8^{\mathrm{a}}$ & $30.5 \pm 1.4^{\mathrm{a}}$ & - \\
$\mathrm{NPF}_{1}$ & $60.9 \pm 2.1^{\mathrm{b}}$ & $10.2 \pm 2.3^{\mathrm{ab}}$ & $31.7 \pm 2.2^{\mathrm{ab}}$ & 3.7 \\
$\mathrm{NPF}_{2}$ & $61.5 \pm 0.3^{\mathrm{b}}$ & $12.5 \pm 0.9^{\mathrm{a}}$ & $31.5 \pm 0.8^{\mathrm{a}}$ & 4.8 \\
$\mathrm{PF}_{1}$ & $64.9 \pm 0.4^{\mathrm{a}}$ & $7.3 \pm 1.3^{\mathrm{b}}$ & $30.8 \pm 0.7^{\mathrm{a}}$ & 6.8 \\
$\mathrm{PF}_{2}$ &
\end{tabular}

$\mathrm{NPF}_{1}$ : non par-fried (control), $\mathrm{NPF}_{2}$ : non par-fried with $0.1 \% \mathrm{CP}$

$\mathrm{PF}_{1}$ : par-fried (control), $\mathrm{PF}_{2}$ : par-fried with $0.1 \% \mathrm{CP}$

${ }_{a, b}$ Different alphabets within the same column are significantly different by Tukey's test $(\mathrm{p}<0.05)$.

Values are mean \pm SD of triplicates.

Colour is an important quality attribute to curry puffs. According to Melito and Farkas [12], a dark-coloured crust was due to the high heat flux on the surface of curry puffs during frying. Thus, Maillard reaction occurred and produced darker-coloured crumb. In addition, the oil colour turns darker with repeated frying due to the chemical reactions that resulted from oxidation and browning of pigment when frying the potatoes [25]. Thus, the used oil needs to be discarded in order to maintain the end-product quality.

\subsection{Weight loss and image analysis}

Weight loss of curry puffs was observed in four consecutive weeks. Ice crystals started to develop on the surfaces of curry puffs after freezing at $-18^{\circ} \mathrm{C}$. During the storage, the weight loss rate was fairly constant with time. According to Table 5, there were significant differences $(\mathrm{p}<0.05)$ of weight loss between the $\mathrm{PF}$ and NPF samples during the 4-week cycle.

Table 5: Weight loss of frozen curry puff during 4 weeks of storage at $18^{\circ} \mathrm{C}$

\begin{tabular}{ccccc}
\hline $\begin{array}{c}\text { Types of } \\
\text { Sample }\end{array}$ & \multicolumn{4}{c}{ Weight Loss $(\%)$} \\
& Week 1 & Week 2 & Week 3 & Week 4 \\
\cline { 2 - 5 } & $0.2 \pm 0.0^{\mathrm{aC}}$ & $0.4 \pm 0.0^{\mathrm{aB}}$ & $0.4 \pm 0.0^{\mathrm{aAB}}$ & $0.5 \pm 0.0^{\mathrm{aA}}$ \\
$\mathrm{NPF}_{1}$ & $0.2 \pm 0.0^{\mathrm{aC}}$ & $0.4 \pm 0.0^{\mathrm{aB}}$ & $0.4 \pm 0.0^{\mathrm{aAB}}$ & $0.5 \pm 0.0^{\mathrm{aA}}$ \\
$\mathrm{NPF}_{2}$ & $0.1 \pm 0.0^{\mathrm{bB}}$ & $0.2 \pm 0.04^{\mathrm{bA}}$ & $0.2 \pm 0.0^{\mathrm{bA}}$ & $0.3 \pm 0.0^{\mathrm{bA}}$ \\
$\mathrm{PF}_{1}$ & $0.1 \pm 0.0^{\mathrm{bC}}$ & $0.2 \pm 0.0^{\mathrm{bB}}$ & $0.2 \pm 0.0^{\mathrm{bAB}}$ & $0.3 \pm 0.0^{\mathrm{bA}}$ \\
$\mathrm{PF}_{2}$ &
\end{tabular}

$\mathrm{NPF}_{1}$ : non par-fried (control), $\mathrm{NPF}_{2}$ : non par-fried with $0.1 \% \mathrm{CP}$,

$\mathrm{PF}_{1}$ : par-fried (control), $\mathrm{PF}_{2}$ : par-fried with $0.1 \% \mathrm{CP}$

${ }^{a, b}$ Different small alphabets within the same column are significantly different by Tukey's test $(\mathrm{p}<0.05)$.

A-C Different capital letters within the same row are significantly different by Tukey's test $(\mathrm{p}<0.05)$.

Values are mean \pm SD of triplicates.

On the fourth week, $\mathrm{NPF}_{1}$ and $\mathrm{NPF}_{2}$ samples lost a high percentage of weight compared to both $\mathrm{PF}_{1}$ and $\mathrm{PF}_{2}$ samples, with a weight loss of only $0.3 \%$ each. Insignificant weight loss $(p>0.05)$ between $\mathrm{NPF}_{1}$ and $\mathrm{NPF}_{2}$ samples were observed from week one till four. However, $\mathrm{PF}_{1}$ and $\mathrm{PF}_{2}$ samples showed significant weight loss during week one till three. Phimolsiripol et al. [28] stated that freezing and thawing will lead to structural changes and damage to the gluten network of dough. The freeze-thaw procedure was also reported to damage the crumb texture and gluten fibril [29]. In addition, a high number of freeze-thaw cycles may coarsen the gluten of baked bread prepared from the frozen dough [30], thus contributing to undesirable texture for consumption. Park et al. [31] stated that the increase in storage time may result in decreased moisture content due to the removal of water during the frozen stage. The significant weight loss $(p<0.05)$ between the NPF and PF samples might be due to a dissimilar rate of heat transfer caused by the differences of a mass transfer medium on each sample surface [32]. All curry puffs were exposed to temperature fluctuation for four weeks and the image was monitored 
weekly via a microscope to observe the formation of black spots on the surface of curry puffs. Figure 1 shows the observation of curry puffs on the first and fourth week of the freeze-thaw cycle. Dark spots were detected on the surface of $\mathrm{NPF}_{1}$ curry puff dough after the fourth cycle. However, no dark spot was detected on $\mathrm{NPF}_{2}, \mathrm{PF}_{1}$, and $\mathrm{PF}_{2}$ curry puffs during the 4-week cycle.

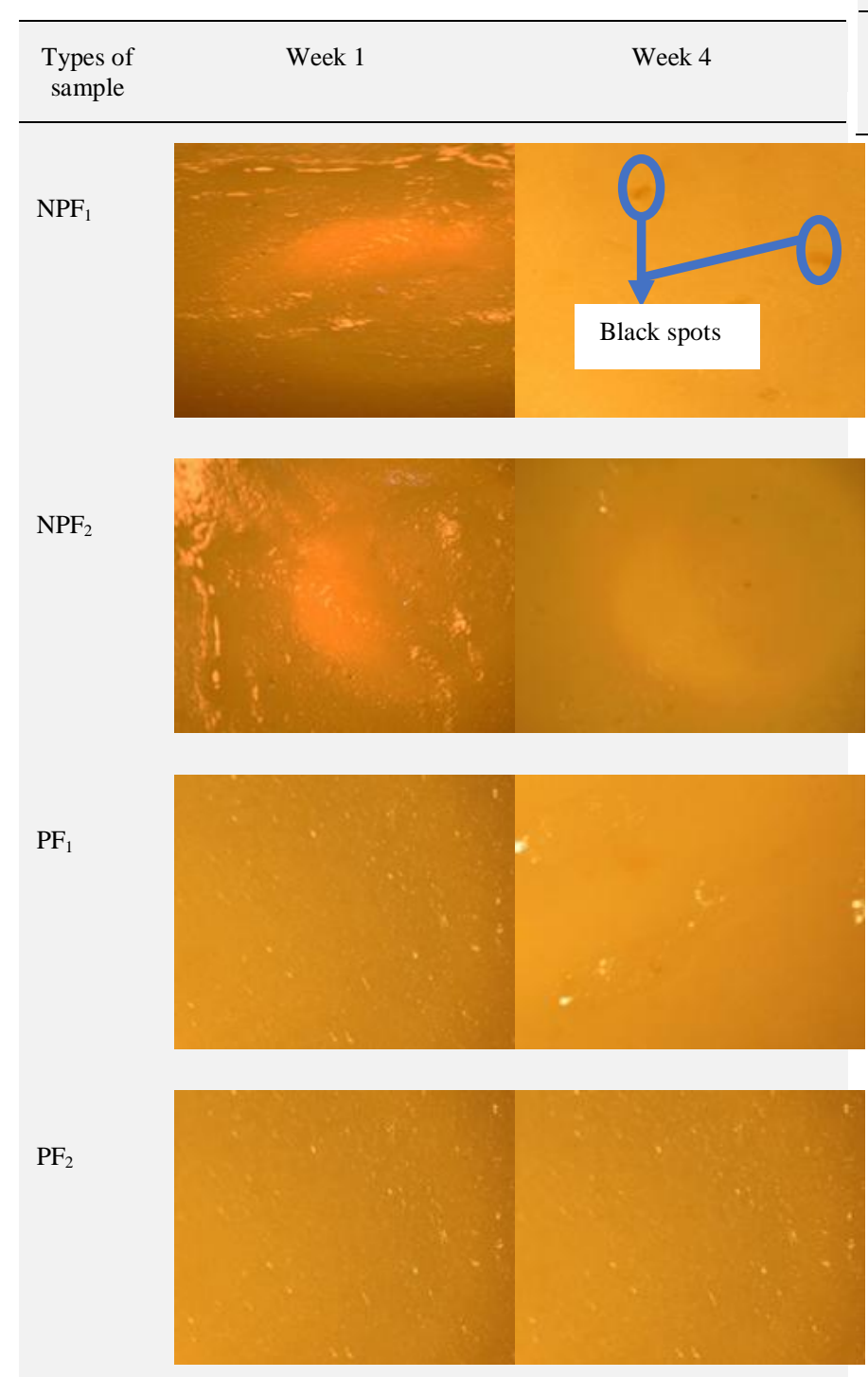

Fig. 1: Observation of black spot via a microscope $(40 \times)$ during freezethaw stage

\subsection{Sensory Evaluation by Consumer Panellists}

The evaluation was conducted by 50 untrained consumer panellists who consisted of $50 \%$ working adults and $50 \%$ of students. Approximately 70\% Malay, 14\% Chinese, 10\% Indians, and $6 \%$ foreigners were selected to be the panellists. Table 6 shows no significant difference $(p>0.05)$ of scores for all tested attributes (colour, texture, taste, overall acceptability) between NPF and PF samples. This finding (colour attribute) was similar to colour evaluation by an instrument of $b$ value (yellowness index) with no significant difference found $(p>0.05)$ as in Table 4 . Both instrument and panellists were not able to detect any colour differences between NPF and PF curry puffs. Both NPF and PF samples had a distinct surface texture after the frying process. The panellists commented the fried PF has a smoother surface than NPF curry puff. Therefore, it can be concluded that consumers were unable to detect the differences in taste, and overall acceptability (with and without the addition of calcium propionate) between NPF and PF curry puffs. All the samples were fairly ac- cepted by this group of consumers. Results indicate that there is a possibility to commercialize par-fried curry puff locally and internationally.

Table 6: Sensorial characteristics of NPF and PF curry puffs

\begin{tabular}{ccccc}
\hline $\begin{array}{c}\text { Type of } \\
\text { sample }\end{array}$ & Colour & Texture & Taste & $\begin{array}{c}\text { Overall } \\
\text { Acceptability }\end{array}$ \\
\hline $\mathrm{NPF}_{1}$ & $6.5 \pm 1.3^{\mathrm{a}}$ & $6.4 \pm 1.6^{\mathrm{a}}$ & $6.9 \pm 1.1^{\mathrm{a}}$ & $6.7 \pm 1.0^{\mathrm{a}}$ \\
$\mathrm{NPF}_{2}$ & $6.8 \pm 1.2^{\mathrm{a}}$ & $6.6 \pm 1.9^{\mathrm{a}}$ & $7.0 \pm 1.3^{\mathrm{a}}$ & $6.9 \pm 1.4^{\mathrm{a}}$ \\
$\mathrm{PF}_{1}$ & $6.9 \pm 1.3^{\mathrm{a}}$ & $7.0 \pm 1.4^{\mathrm{a}}$ & $7.0 \pm 1.2^{\mathrm{a}}$ & $7.1 \pm 1.3^{\mathrm{a}}$ \\
$\mathrm{PF}_{2}$ & $6.6 \pm 1.4^{\mathrm{a}}$ & $6.8 \pm 1.3^{\mathrm{a}}$ & $6.7 \pm 1.2^{\mathrm{a}}$ & $6.8 \pm 1.0^{\mathrm{a}}$
\end{tabular}

$\mathrm{NPF}_{1}$ : non par-fried (control), $\mathrm{NPF}_{2}$ : non par-fried with $0.1 \% \mathrm{CP}$,

$\mathrm{PF}_{1}$ : par-fried (control), $\mathrm{PF}_{2}$ : par-fried with $0.1 \% \mathrm{CP}$

Similar alphabets within the same column show the insignificant difference by Tukey's test $(p>0.05)$.

Values are mean \pm SD of triplicates.

\section{Conclusion}

The moisture content in uncooked $\mathrm{NPF}_{1}$ curry puff was significantly the highest $(\mathrm{p}<0.05)$ compared to $\mathrm{NPF}_{2}, \mathrm{PF}_{1}$, and $\mathrm{PF}_{2}$ curry puffs. Meanwhile, oil uptake shows significant differences $(\mathrm{p}<0.05)$ between NPF and PF curry puffs. The $\mathrm{NPF}_{1}$ and $\mathrm{NPF}_{2}$ curry puffs had higher oil uptake compared to $\mathrm{PF}_{1}$ and $\mathrm{PF}_{2}$ curry puffs. Total polar content (TPC) in fried oil shows linear relationship upon repeated frying. The TPC in oil from the first time of frying until the 15th time frying increased significantly but was still at an acceptable level. There was a significant difference in weight loss $(p<0.05)$ between the uncooked NPF and PF curry puffs on the fourth week of the freeze-thaw cycle. Uncooked $\mathrm{NPF}_{1}$ and $\mathrm{NPF}_{2}$ curry puffs had significantly higher weight loss than $\mathrm{PF}_{1}$ and $\mathrm{PF}_{2}$ curry puffs. Image analysis showed black spots on the uncooked $\mathrm{NPF}_{1}$ curry puff on the fourth-week cycle. The colour of the curry puff surface was analyzed via colourimeter and sensorial evaluation. Both consumers and instrument showed no significant difference in the colour attributes of fried curry puff. Consumers were not able to detect the differences between NPF and PF curry puffs in terms of texture, appearance, taste, and overall acceptability. Thus, par-frying with the addition of $\mathrm{CP}$ may be adapted for the production of frozen curry puff to maintain its quality and preserve the product during distribution and frozen storage.

\section{Acknowledgement}

This project was done in fulfilment of Private-Public Research Network (PPRN) grant (Voucher No. B0007). The authors are grateful for the financial support provided by the Ministry of Higher Education of Malaysia; Doana Frozen Food, Johor; and Universiti Putra Malaysia (UPM).

\section{References}

[1] Sloan AE (2015), Top 10 Food Trends. Food Technology. 69(4), http://www.ift.org/foodtechnology/pastissues/2015/april/features/th e-top-ten-food-trends.aspx?page=viewall.

[2] Kotzekidou P (2013), Microbiological examination of ready-to-eat foods and ready-to-bake frozen pastries from university canteens. Food Microbiology 34, 337-343

[3] Kasetsart J (2009), Shelf life determination of frozen bread dough stored under fluctuating temperature conditions. National Science 43, 187-197.

[4] Saranjan P \& Geetha M (2012), Microbial spoilage of bakery products and its control by preservatives. International Journal of Pharmaceutical and Biology Archive 3(1), 38-48.

[5] Guynot ME, Ramos AJ, Sala D, Sanchis V \& Marin S (2002), Combined effects of weak acid preservatives, $\mathrm{pH}$ and water activity on growth of Eurotium species on a sponge cake. International Journal Food Microbiology 76, 39-49.

[6] EFSA (European Food Safety Authority) (2014), Re-evaluation of propionic acid - propionates (E 280-283). The EFSA Journal 438, $1-54$. 
[7] Belz MCE, Mairinger R, Zannini E, Ryan LAM, Cashman KD \& Arendt EK (2012), The effect of sourdough and calcium propionate on the microbial shelf life of salt reduced bread. Applied Microbial Biotechnology 96, 493-501.

[8] Khaldun MAZ, Bahruddin S, Hashim NH, Afidah AR \& Khairuddin MT (2010), Determination of propionates and propionic acid in bakery products using gas chromatography. International Food Research Journal 17, 1107-1112.

[9] Kirbaslar Şİ, Selin Ş \& Mehmet B (2006), (Liquid + liquid) equilibria of (water + propionic acid + alcohol) ternary systems. Journal of Chemical Thermodynamics 38, 1503-1509.

[10] Lonn WAM, Visser JE, Linssen JPH, Somsen DJ, Jan Klok H \& Voragen AGH (2007), Effect of pre-drying conditions on the crispness of French fries. European Food Research Technology 225 , 929-935.

[11] Raj T, Kar JR \& Singhal RS (2016), Development of par-fried frozen samosas and evaluation of its post-storage finish frying and sensory quality. Journal of Food Processing and Preservation 41(4), 1745-4549.

[12] Melito HS \& Farkas BE (2013), Effect of infrared finishing process parameters on physical, mechanical, and sensory properties of parfried, infrared-finished gluten-free donuts. Journal of Food Engineering 117, 399-407.

[13] AOAC (2006), Official method of analysis of AOAC international 18th edition. Virginia, USA: Association of Official and Analytical Chemist International.

[14] Lemos MA \& Sivaramareddy A (2013), Effect of oil quality on the levels of total phenolics, total anthocyanins and antioxidant activity of French fries. Inside Food Symposium. Leuven, Belgium.

[15] Ferreira DR, Beleia ADP \& Silva RSSF (2014), Alterations of palm oil (Elaeis guineensis) in the continuous industrial par frying of breaded chicken snacks. Journal of Food Science and Technology 34(1), 32-37.

[16] Ding X, Wang L, Qian H, Qi X \& Xiao J (2015), Effect of barley antifreeze protein on thermal properties and water state of dough during freezing and freeze-thaw cycles. Food Hydrocolloids 47, 3240.

[17] Mohamed AAA, Jowitt R \& Brennan JG (1982), Sensory and instrumental measurement of food crispness: in high moisture food. Journal of Food Engineering 1(2), 123-147.

[18] Sanz T, Primo-Martin C \& Van Vliet T (2007), Characterization of crispiness of French fries by fracture and acoustic measurements, effect of pre-frying and final frying times. Food Research International 40, 63-70.

[19] Mellema M (2003), Mechanism and reduction of fat uptake in deep-fat fried foods. Trends in Food Science and Technology 14, 364-373.

[20] Deodra NS, Deswal A \& Madhavan S (2016), Application of rosemary (Rosmarinus officinalis 1.) based natural antioxidant during deep fat frying of noodle. Turkish Journal of Agriculture-Food Science and Technology 4(4), 298-304.

[21] Chatzilazarou A, Gortzi O, Lalas S Zoidis E \& Tsaknis J (2006), Physicochemical changes of olive oil and selected vegetable oils during frying. Journal of Food Lipid 13, 27-35.

[22] Chen WA, Chiu CP, Cheng WC, Hsu CK \& Kuo MI (2013), Total polar compounds and acid values of repeatedly used frying oils measured by standard and rapid methods. Journal of Food and Drug Analysis 21, 58-65.

[23] Rhee KS, Anderson LM \& Sams AR (1996), Lipid oxidation potential of beef, chicken, and pork. Journal of Food Science 61, 8-12.

[24] Fritsch CW (1981), Measurements of frying fat deterioration: A brief review. Journal of the American Oil Chemists' Society 58, 272-274.

[25] Aladedunye FA \& Przybylski R (2009), Protecting oil during frying: A comparative study. European Journal of Lipid Science and Technology 111, 893-901.

[26] Weisshaar R (2014), Quality control of used deep-frying oils. European Journal of Lipid Science and Technology 116, 716-722.

[27] Melck J, Druzbikova H, Valasek P, Sochor J, Jurikova T, Borkovcova M, Baron M \& Balla S (2015), Assessment of total polar materials in frying fats from Czech restaurants. Italian Journal Food Science 27, 160-165.

[28] Phimolsiripol Y, Siripatrawan U, Tulyathan V \& Cleland DJ (2008), Effects of freezing and temperature fluctuations during frozen storage on frozen dough and bread quality. Journal of Food Engineer ing 84, 48-56.

[29] Naito S, Fukami S, Mizokami Y, Ishida N, Takano H \& Koizumi $M$ (2004), Effect of freeze-thaw on the gluten fibrils and crumb grain structure of breads made from frozen doughs. Cereal Chemistry $81,80-86$.

[30] Berglund PT \& Shelton DR (1993), Effect of frozen storage on firming properties of breads baked from frozen doughs. Cereal Foods World 38, 89-90.

[31] Park EY, Jang SB \& Lim ST (2016), Effect of fructooligosaccharide addition on baking quality of frozen dough. Food Chemistry 213, 157-162.

[32] Phimolsiripol Y, Siripatrawan U \& Cleland DJ (2011), Weight loss of frozen bread dough under isothermal and fluctuating temperature storage conditions. Journal of Food Engineering 106, 134-143. 